\title{
ESPECTROMETRIA GAMA DE ALTA RESOLUÇÃo APLICADA À AVALIAÇÃO DE DEPÓSITOS
}

\section{ALUVIONARES}

\author{
E.M.Pascholati ${ }^{1}$ \\ G.Amara/ ${ }^{2}$ \\ A.F.C.Morais Filho ${ }^{3}$ \\ P.R.Pascholati ${ }^{4}$ \\ Helio Shimada ${ }^{5}$
}

A avaliação de teores de minerais de interesse, em depósitos aluvionares, não é tarefa simples. Freqüentemente, aqueles minerais ocorrem em concentrações de algumas partes por milhão, próximas aos limites de detecção de técnicas analfticas. Para alguns minerais, a avaliação só é possivel através de lavra experimental. Por esses motivos, muito esforço é dedicado ao desenvolvimento de métodos indiretos para a avaliação de depósitos aluvionares de cassiterita, ouro e diamantes.

A idéia básica da pesquisa é verificar o nível de correlação entre os teores de elementos ou minerais de interesse e os teores de urânio e tório da mineralogia detritica associada. Caso essa correlação seja elevada, a gamaespectrometria de campo (inclusive aérea) ou de laboratório poderá ser um importante método indireto para a avaliação daqueles depósitos.

O presente trabalho apresenta os resultados preliminares, obtidos para seis amostras, provenientes de Rondônia, fornecidas pela Companhia Estanffera do Brasil, para as quais o

\footnotetext{
1 Instituto de Geociências, UNICAMP.

${ }^{2}$ Departamento de Paleontologia e Estratigrafia, Instituto de Geociências, USP/Instituto de Geociências, UNICAMP.

${ }^{3}$ Graduação, Instituto de Física, USP.

${ }^{4}$ Instituto de Física, USP.

5 CONAMI.
} 
teor em estanho foi determinado quimicamente. Os teores de urânio e tório foram determinados por espectrometria gama de alta resolução, usando-se detector de germânio hiper puro. Esta técnica permite a identificação de diversas linhas de energia associadas à desintegração daqueles dois elementos. Com isso, obtem-se maior sensibilidade na avaliação dos teores. Os resultados foram tratados no programa STATGRAF, para obtenção de correlação, gráficos $x-y$ e regressão linear simples. Como existem incertezas tanto na determinação de Sn, como de U e Th, foi aplicado o programa de regressão por Monte Carlo, desenvolvido por um dos autores (GA).

O coeficiente de correlação produto-momento (Pearson), entre o Sn e o Th foi de 0,99907, enquanto que entre o $\mathrm{Sn}$ e o $\cup$ foi de 0,98937 , portanto muito bons. Os gráficos $x-y$ entre esses pares de elementos mostram relacionamento fortemente linear no primeiro caso e levemente exponencial no segundo. O melhor resultado para o tório já era esperado, pois esse elemento apresenta-se sempre na forma tetravalente positiva, pouco solúvel. O urânio, por outro lado, pode ser oxidado para a forma hexavalente positiva, bastante solúvel, o que explicaria sua maior variabilidade.

Os resultados preliminares, ora relatados, são bastante promissores, indicando que a gamaespectrometria pode ser uma importante ferramenta auxiliar, para a avaliação de depósitos aluvionares. O projeto prossegue com a análise mineralógica da fração pesada e testes em amostras desconhecidas. Caso amostras sejam disponfveis, serão examinados outros tipos de depósitos. 